\title{
Potentiometric Determination of Moxifloxacin by ZnO Nanorodes Modified ion Selective Electrode
}

\section{Malaz Osman Idress ${ }^{1}$, Abdalla A. Elbashir ${ }^{1 *}$ and Omer Nur ${ }^{2}$}

${ }^{1}$ Faculty of Science, Department of Chemistry, University of Khartoum, Khartoum 11115, Sudan

${ }^{2}$ Department of Science and Technology, Campus Norköping, Linköping University, SE-601 74 Norrköping, Sweden

*Corresponding author: Prof. Abdalla Ahmed Elbashir, Faculty of Science, Department of Chemistry, University of Khartoum, Khartoum 11115, Sudan, Tel: +2495661431431; E-mail: aaelbashir@uofk.edu

Received date: Sep 27, 2017; Accepted date: Oct 18, 2017; Published date: Oct 23, 2017

Copyright: ( 2017 Idress MO, et al. This is an open-access article distributed under the terms of the Creative Commons Attribution License, which permits unrestricted use, distribution, and reproduction in any medium, provided the original author and source are credited.

\begin{abstract}
Potentiometric determination of moxifloxacin (Moxi) by ion selective electrode based on $\mathrm{ZnO}$ nanorods incorporation with HPß-CD as sensing ionophore and (KTFPB) potassium tetrakis- (3,5(triflouromethyl) phenyl borate ion as anionic site (additive) in polyvinyl chloride (PVC) membrane, without inner reference solution was developed. The sensor shows nearly nernstian response over a concentration range $\left(5 \times 10^{-8} \mathrm{M}\right.$ to $\left.1 \times 10^{-2} \mathrm{M}\right)$ with a slope of $21.9 \pm 0.16 \mathrm{mv}$ decade $^{-1}$ of concentration with a limit of detection (LOD) $0.127 \mu \mathrm{M}$. The electrode exhibits a fast dynamic response of $2 \mathrm{~s}$ for a period of 6 months without significant change in its characteristics with excellent stability and sensitivity toward inorganic species. The method is accurate and precise as indicated by the mean recoveries $99.5 \%$ with RSD less than $2 \%$. The proposed method was successfully applied for the determination of Moxi in pure form and its pharmaceutical formulations.
\end{abstract}

Keywords: Potentiometric; Ion selective electrode; $\mathrm{ZnO}$ nanorode; Moxi

\section{Introduction}

Moxifloxacin (Moxi) chemically is 1-cyclopropyl-7-(2,8diazobicyclo[4.3.0]nonane)-6-fluoro-8-methoxy-1,4-dihydro-4-oxo-3quinoline carboxylic acid Figure 1, is a synthetic fourth generation fluoroquinolone (fluorinated derivative of the quinolone). Moxi is active against broad spectrum of antibacterial agent, encompassing Gram-negative, Gram-positive bacteria and also antibiotic resistant streptococcus pneumonia [1,2]. The bactericidal action of Moxi results from trapping of enzymes on DNA and lethal release of doublestranded breaks, thereby inhibiting of cell replication [3].

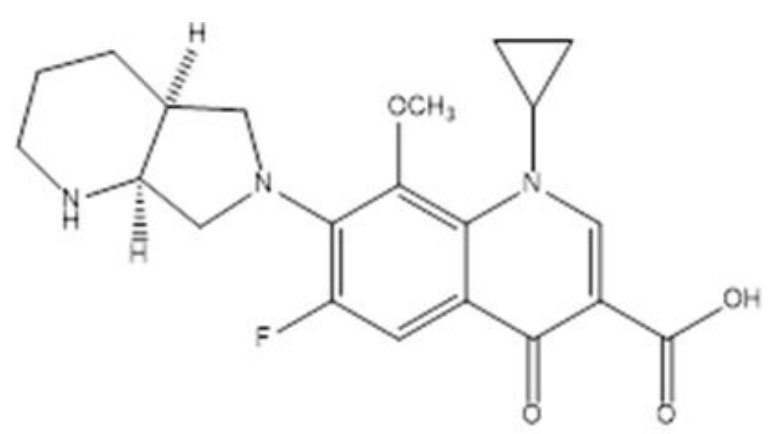

Figure 1: Chemical structure of Moxifloxacin hydrochloride.

Various analytical methods have been cited in literature for Moxi determinations including spectrophotometry, spectrofluorimetry, atomic absorption spectrometry, conductometry, voltammetry [4-10], high performance liquid chromatography-ultraviolet (HPLC-UV),
HPLC-fluorescence(HPLC-Fl), capillary electrophoresis(CE), and HPLC-mass spectrometry (HPLC-MS) [4-17].

Potentiometric sensors are easy to miniaturize and provides a large dynamic range. In conventional ion selective electrodes, polyvinyl chloride (PVC) is the most commonly used matrix as the selective membrane. The ion-selective membrane exhibits the selectivity with which the sensing material responds to the analyte and an electrochemical equilibrium is reached. The resulting potential difference, formed between the phases, will then be governed by the activity of this specific ion in the two solution phases [17-19].

Different potentiometric methods using ion selective electrodes for determination of Moxi were reported [20-23]. Hefnawy et al. developed PVC membrane sensors for analysis of Moxi. The sensing membranes incorporate ion association complexes of Moxi-cation and sodium tetraphenyl borate (NaTPB), phosphomolybdic acid (PMA) and phosphotungstic acid (PTA) as electroactive materials [21]. The sensors showed good discrimination of Moxi from several inorganic and organic compounds. Elghobashy et al. Constructed Moxi selective electrodes with 2-nitrophenyl octyl ether as a plasticizer in a polymeric matrix of PVC. The Sensors were fabricated using tetrakis (4chlorophenyl) borate (TpClPB) as an anionic exchanger with and without incorporation of an ionophore [22]. The proposed sensors were successfully applied for the determination of Moxi in bulk powder, pharmaceutical formulation, and biological fluids.

$\mathrm{ZnO}$ nanowires, nanorods and nanotubes have gained much attraction due to their high surface-to-volume ratio which makes them extremely sensitive to minute surface changes; also they have excellent chemical stability [24]. Moreover, one-dimensional $\mathrm{ZnO}$ nanostructures are promising for bio and chemical sensing due to their ease to grow vertically on almost any substrate there high sensitivity, low cost, simplicity and low power consumption [24,25]. 
Citation: Idress MO, Elbashir AA, Nur O (2017) Potentiometric Determination of Moxifloxacin by ZnO Nanorodes Modified ion Selective Electrode. Pharm Anal Acta 8: 566. doi:10.4172/2153-2435.1000566

Page 2 of 6

In this study potentiometric $\mathrm{ZnO}$ nanorods based ion selective electrode without inner reference solution for a simple, sensitive, and rapid determination of Moxi in pharmaceutical formulations is illustrated. Ion selective electrode consisted of PVC, dibutyl phthalate, 2 -Hydroxypropyl)- $\beta$-cyclodextrin (HP $\beta$-CD) and potassium tetrakis (3,5 (triflouro methyl)phenyl)borate (KTFPB) as matrix, plasticizer, sensing ionophore and anionic additive, respectively were used.

\section{Materials and Methods}

\section{Chemicals and reagent}

Moxifloxacin hydrochloride was obtained from (98\%, Bayer AG, Leverkusen Germany), HP $\beta C D$ (ionophore), tetrakis (3,5(triflouro methyl)phenyl) borate (KTFPB) (additive), PVC (high molecular weight), dibutyl phthalate (a plasticizer), zinc acetate ( $\mathrm{ZnAc}$ ), Hexamethylenetetramine (HMTA) ware purchased from sigma Aldrich (St. Louis, USA), silver wire ( $0.3 \mathrm{~mm}$ diameter), $\mathrm{Na}_{2} \mathrm{HPO}_{4}$, $\mathrm{H}_{3} \mathrm{PO}_{4}, \mathrm{KOH}$, acetone, isopropanol, tetrahydrofuran (THF), methanol, (all solvent with HPLC grade), Avelox tablet (Bayer Schering pharma) TRT06R7 labeled to contain $400 \mathrm{mg}$ Moxi per tablet were purchased from local market, Deionized water.

\section{Instrument and apparatus}

$\mathrm{pH} / \mathrm{mv}$ meter (PHS-3E) (China), Ag/AgCl reference electrode $(\Omega$ metrohm. Autolab, inner and outer filling by $\mathrm{KCl} 3 \mathrm{M}$. (Netherlands), sensitive balance, magnetic hot plate, thermometer, oven, SEM (Zeiss Evo LS 10, Germany).

\section{Seed and growth $\mathrm{ZnO}$ nanorods}

$\mathrm{ZnO}$ nanorods was grown by low temperature aqueous chemical method [25]. A silver wire $(0.3 \mathrm{~mm})$ was cut in the length of $5 \mathrm{~cm}$ and cleaned by acetone and isopropanol for $2 \mathrm{~min}$ in each solution followed by rinsing with deionized water and left to dry at room temperature. The silver wire was immersed three times in a seed solution prepared by mixing alcoholic solutions of $\mathrm{KOH}$ added drop wise to heated, stirred $0.03 \mathrm{M}$ of zinc acetate the resulting solution was kept under stirring for 2 hours at $60^{\circ} \mathrm{C}$ prior dipping, the wires was left to dry at room temperature. The $\mathrm{ZnO}$ was grown by suspending the pre-coated Ag wire in aqueous solutions contains $0.025 \mathrm{M} \mathrm{ZnAc}$ with equimolar concentration of HMTA. The beaker was placed in preheated oven at $70^{\circ} \mathrm{C}$ to 5 hours. The wires were cooled down, washed by deionized water and left to dry overnight. The $\mathrm{ZnO}$ nanorods was characterized by SEM (Zeiss Evo LS 10, Germany) Figure 2.

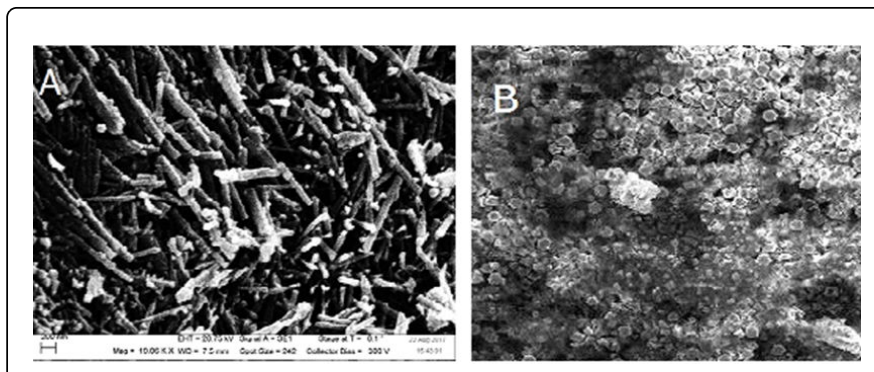

Figure 2: A, B) SEM at different magnifications and view of the $\mathrm{ZnO}$ nanorodes grown on $\mathrm{Ag}$ wire hydrothermal aqueous chemical method.

\section{Coating $\mathrm{ZnO}$ nanorods with ion selective membrane}

$\mathrm{ZnO}$ nanorods were coated by ion selective membrane by mixing $33 \%$ PVC, 66\% DBP plasticizer, $1.2 \% \mathrm{HP} \beta-\mathrm{CD}$ (ionophore), $0.4 \%$ KTFPB (ionic additive) in $5 \mathrm{ml} \mathrm{THF}$. The $\mathrm{ZnO}$ coated wires was dipped twice into a prepared solution, after each dip the electrode was left to dry at room temperature, then the electrode was conditioned into $1 \times$ $10^{-3} \mathrm{M}$ of Moxi standard solution for 24 hour prior to use. The membrane was characterized by SEM (Zeiss Evo LS 10, Germany) Figure 3.
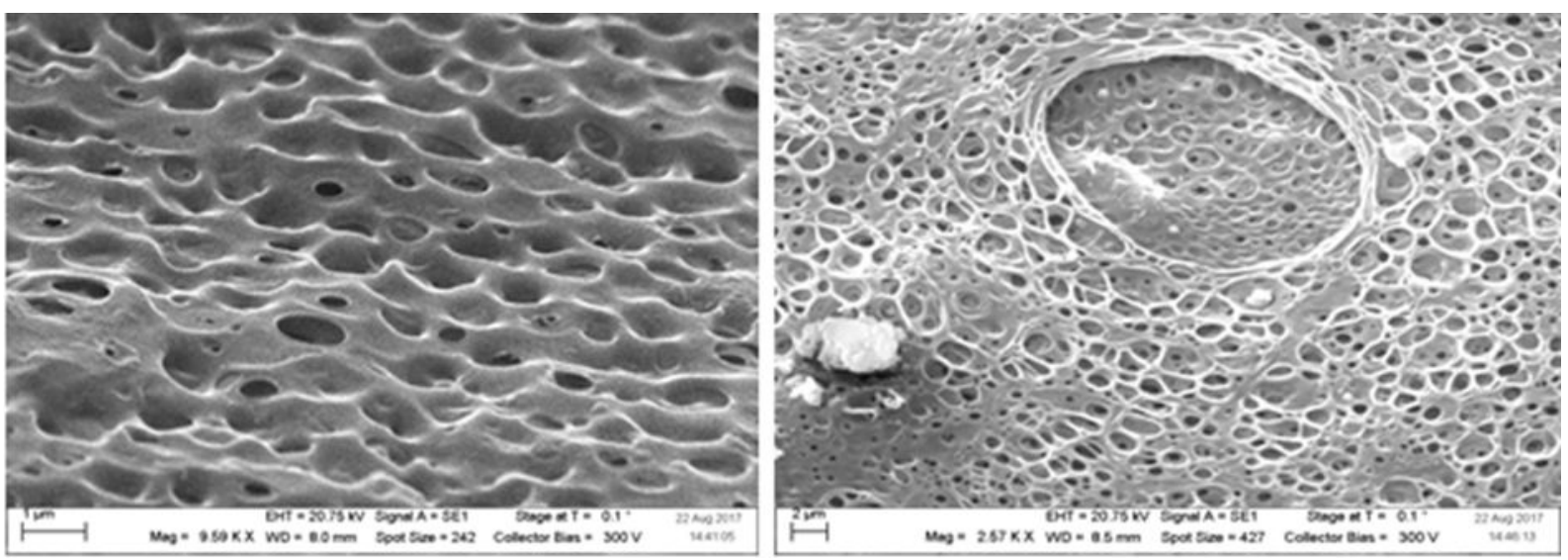

Figure 3: Presents ion selective membrane with KTFPB additive with different magnification.

\section{Standard drug solutions}

Stock standard solutions $0.01 \mathrm{M}$ Moxi.HCl $(\mathrm{Mw}=437.89 \mathrm{~g} / \mathrm{mol})$ was prepared by dissolving accurate weight in deionized water, this solution was kept in the dark at $4^{\circ} \mathrm{C}$ and it was found that it was stable for several weeks. Working solutions ranging 0.001-10000 $\mu \mathrm{M}$ were prepared by serial dilution of the stock solution by deionized water. The testing series was prepared by adding adequate amount of $(0.2 \mathrm{M})$ phosphate buffer $\left(\mathrm{H}_{3} \mathrm{PO}_{4} / \mathrm{Na}_{2} \mathrm{HPO}_{4}\right)[\mathrm{pH}=2 ; 0.2 \mathrm{M}]$ and desired 
Citation: Idress MO, Elbashir AA, Nur O (2017) Potentiometric Determination of Moxifloxacin by ZnO Nanorodes Modified ion Selective

volume of drug stock solution and the volume completed to mark by deionized water.

\section{Electrochemical measurements}

In a complete potentiometric cell, the Moxi- $\mathrm{ZnO}$-selective electrode was used in conjunction with $\mathrm{Ag} / \mathrm{AgCl}$ reference electrode (inner and outer filling by $\mathrm{KCl} 3 \mathrm{M}$ ). The electrochemical potential between the Moxi-ZnO- selective electrode as cathode and $\mathrm{Ag} / \mathrm{AgCl}$ reference electrode $(\Omega$ metrohm. Autolab, inner and outer filling by $\mathrm{KCl} 3 \mathrm{M})$ as anode was measured with $\mathrm{pH} / \mathrm{mv}$ meter (PHS-3E).

\section{Moxi.TFPB - PVC || Test solution || Ag/AgCl (3M KCl)}

The measured potential was plotted against the logarithm of drug concentration. The electrode was washed with deionized water blotted with tissue paper between measurements.

\section{Results and Discussions}

\section{Optimization conditions}

Effect of $\mathrm{pH}$ : The effect of $\mathrm{pH}$ on the potential response of the Moxi$\mathrm{ZnO}$-ISE was investigated using $1 \times 10^{-4} \mathrm{M}$ solutions in $\mathrm{pH}$ range of 2.0-11.0 using $\mathrm{Na}_{2} \mathrm{HPO}_{4} / \mathrm{H}_{3} \mathrm{PO}_{4}(0.2 \mathrm{M})$ as a buffer solution. The potential readings corresponding to different $\mathrm{pH}$ values were recorded and plotted using the proposed electrode. Increasing in electrode potential was observed in $\mathrm{pH}$ range from 2 to 3 and decreased from $\mathrm{pH} 4$ to 11, Figure 4. These result suggested that the inclusion complex of Moxi and HP $\beta-C D$ was suitable in acidic media because Moxi contains secondary amine that capable to bind with protons presents in acidic media resulting positively charged Moxi ion, which therefore can attracted by anionic tetraphenyl borate group present in the additive (KTFPB) and hence facilities the inclusion between Moxi and $\mathrm{HP} \beta-\mathrm{CD}[21,22]$.

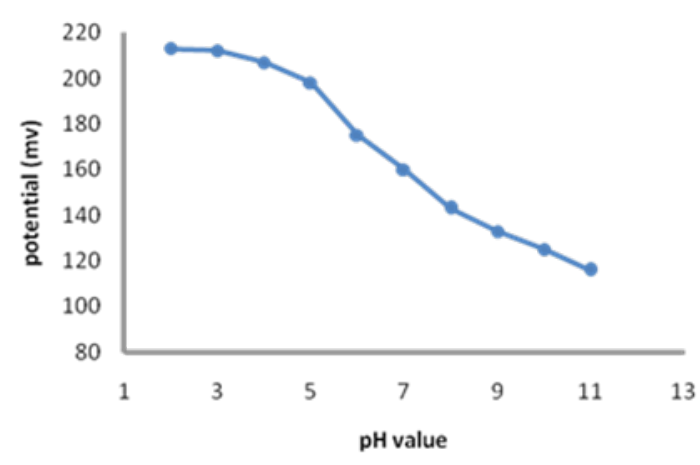

Figure 4: Optimization of $\mathrm{pH}$ for Moxi-TFPB- HP $\beta$-CD, Moxi $1 \times$ $10^{-4} \mathrm{M}$, at room temperature, time $2 \mathrm{sec}$.

Effect of volume of buffer: The effect of volume of buffer on the potential response of the Moxi-ZnO-ISE was studied using $1 \times 10^{-4} \mathrm{M}$ solutions in the range of $(0-10) \mathrm{mL}$ using $\mathrm{Na}_{2} \mathrm{HPO}_{4} / \mathrm{H}_{3} \mathrm{PO}_{4}[\mathrm{pH} 2 ; 0.2$ $\mathrm{M}]$. It was found that the potential increased when buffer adding to Moxi solution without buffer and the potential remains constant with adding extra volume of buffer as shown in Figure 5.

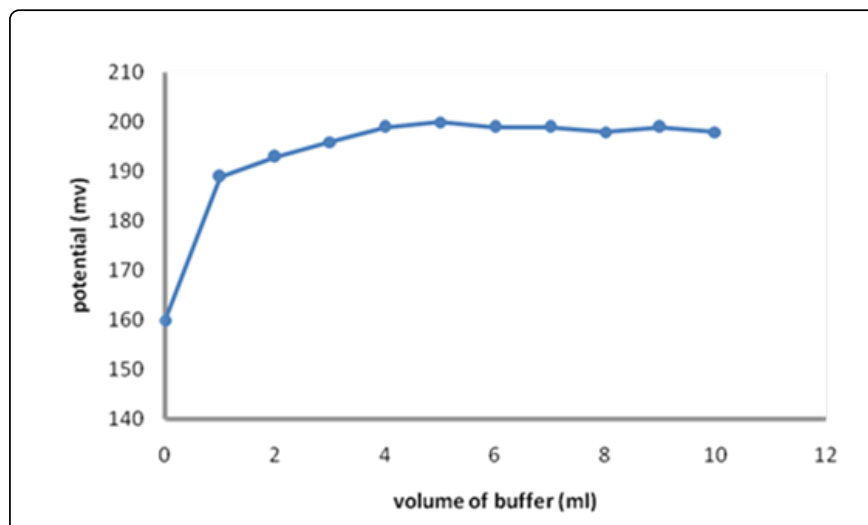

Figure 5: Optimization of buffer volume for Moxi-TFPB- HP $\beta$-CD, Moxi $1 \times 10^{-4} \mathrm{M}$, at room temperature, time, $2 \mathrm{sec}, \mathrm{pH} 2$.

Effect of temperature: The effect of temperature on the potential response of the Moxi-ZnO-ISE was studied using $1 \times 10^{-4} \mathrm{M}$ solutions at the range of temperature $\left(10-80^{\circ} \mathrm{C}\right)$ using thermometer presented in Figure 6. It reveals that the potential increased with increasing temperature of drug solution this could be attributed to potentiometric measurements is equilibrium controlled [26], thus increasing solution temperature is resulting faster equilibrium between the electrode surface and Moxi solution.

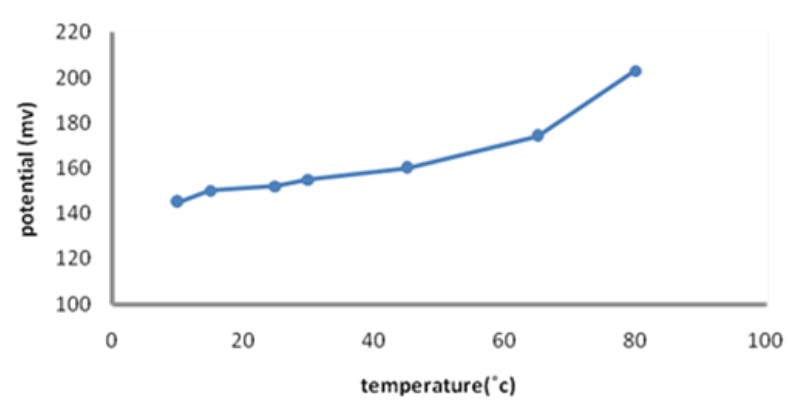

Figure 6: Optimization of temperature for Moxi-TFPB- HP $\beta-C D$, Moxi $1 \times 10^{-4} \mathrm{M}$, time $2 \mathrm{sec}$ and $5 \mathrm{~mL} \mathrm{pH} 2$.

Response time: The response time of potential of the Moxi-ZnO-ISE was studied using $1 \times 10^{-4} \mathrm{M}$ solutions in a period from 0 to 15 second. The potential readings corresponding to time were recorded and plotted using the proposed electrode in Figure 7. The sensor display very fast and stable response within 2 second. 


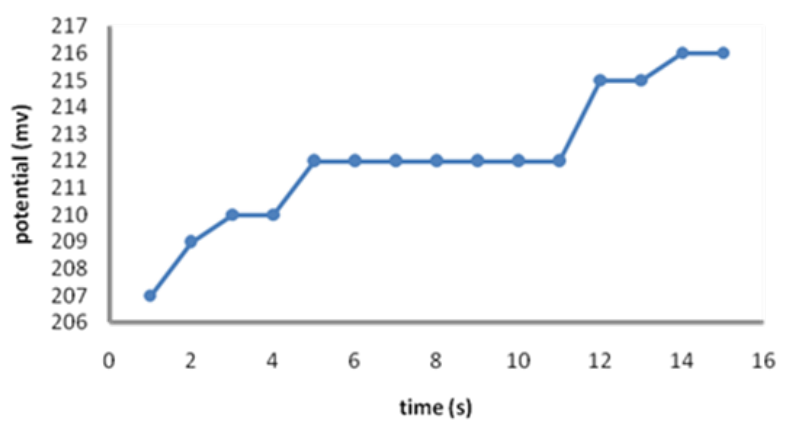

Figure 7: Optimization of response time for Moxi-TFPB- HP $\beta-C D$, Moxi $1 \times 10^{-4} \mathrm{M}$, at room temperature, $5 \mathrm{~mL} \mathrm{pH} 2$.

\section{Electrode composition}

The electrode shows linear nernestian response over a wide range of concentration $0.05-10000 \mu \mathrm{M}$, stable, sensitive and very fast response. This attributed to electrode compositions. The $\mathrm{ZnO}$ nanorods increased the surface area for distribution of the membrane compared if it directly attached to silver wire, thus increased the sensitivity of the electrode and decreases the response time. HP $\beta$-CD is used as sensing ionophore, the most important property of CDs is their ability to form supramolecular inclusion complexes with many appropriately sized organic ions and molecules in aqueous, non-aqueous and mixed media $[27,28]$. The driving forces for the complexation are non-covalent, including vanderWaals forces and directed hydrogen bonding. Water molecules in $\mathrm{CD}$ cavity are displaced by more hydrophobic guest molecules present in the solution to attain a non-polar/non-polar association and decrease of $\mathrm{CD}$ ring strain resulting in a more stable lower energy state [29]. On constructing an ISE, the amount of the sensing ionophore in the electrode matrix should be sufficient to obtain reasonable complexation at the electrode surface that is responsible for the electrode potential [30,31].

The function of KTFPB as lipophilic ionic additives is to promote the interfacial ion exchange kinetics and decrease the electrode resistance through enhancing the ionic mobility in the electrode matrix. The response of ISEs containing ionic sites can be distinguished whether the incorporated ionophore acts as an electrically charged or uncharged carrier $[32,33]$.

\section{Statistical data}

The analytical methods were validated with respect to linearity, limit of detection (LOD), limit of quantification (LOQ) and precision according to ICH [34].

Calibration curve and statistical data for Moxi: The measuring range of a potentiometric sensor was the linear part of the calibration curve as shown in Figure 8. The critical response of the sensor was determined and the results were summarized in Table 1. LOD and LOQ were determined using the formula $\mathrm{LOD}$ or $\mathrm{LOQ}=\mathrm{K} . \mathrm{SDa} / \mathrm{b}$, where $\mathrm{K}=3.3$ for $\mathrm{LOD}$ and 10 for $\mathrm{LOQ}, \mathrm{SDa}$ is the standard deviation of the intercept, and $\mathrm{b}$ is the slope. The values of LOD and LOQ were found to be 0.127 and $0.3836 \mu \mathrm{M}$ respectively. The sensor show nearly nernestian response over the concentration range $0.05-10000 \mu \mathrm{M}$ for Moxi standard solution. Calibration curve slope for electrode were 21.9
$\mathrm{mV}$ decade ${ }^{-1}$. The electrode exhibited a fast dynamic response of $2 \mathrm{~s}$ for a period for more than 6 months without significant change in the electrodes parameters.

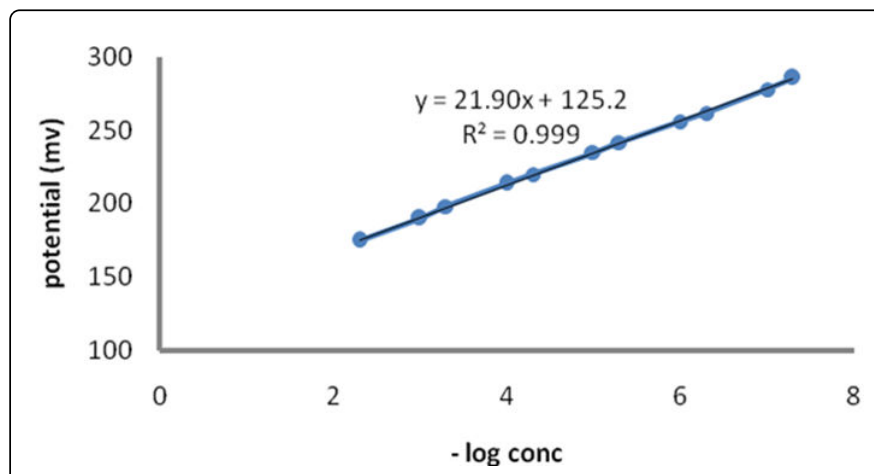

Figure 8: Calibration curve of Moxi-TFPB-HP $\beta C D$, Moxi $1 \times 10^{-4}$ $\mathrm{M}$, at room temperature, time $2 \mathrm{sec}, 5 \mathrm{~mL} \mathrm{pH} 2$.

\begin{tabular}{|l|l|}
\hline Parameter & Value \\
\hline Slope, mv decade-1 & $21.9 \pm 0.16$ \\
\hline Intercept, mv decade-1 & $125.24 \pm 0.84$ \\
\hline Linear Correlation coefficient ( R2 ) & 0.9995 \\
\hline Linear range, $\mu \mathrm{M}$ & $0.05-10000 \mu \mathrm{M}$ \\
\hline LOD, $\mu \mathrm{M}$ & 0.127 \\
\hline LOQ, $\mu \mathrm{M}$ & 0.3836 \\
\hline Response time, second & $>5 \mathrm{~s}$ \\
\hline Life time, month & 6 month \\
\hline *PDL, $\mu \mathrm{m}$ & $0.001 \mu \mathrm{M}$ \\
\hline *PDL= practical detection limit & \\
\hline
\end{tabular}

Table 1: Parameter for Moxi potentiometric method.

Accuracy and precision of the potentiometric method: The accuracy and precision of the proposed method was determined at three concentration levels of Moxi by apply three replicate samples of each concentration. The standard deviations for the results did not exceed $2 \%$ are listed in Table 2, indicating high reproducibility of the results and precision of the method. This good level of precision was suitable for quality control analysis of Moxi and in the pharmaceutical formulations.

\begin{tabular}{|l|l|l|l|}
\hline Concentration & Taken $(-\log \mathbf{c})$ & Found $(-\log \mathbf{c})$ & Recovery $\% \pm$ RSD $^{*}$ \\
\hline $5 \times 10^{-4} \mathrm{M}$ & 3.3 & 3.46 & $104.8 \pm 0.97$ \\
\hline $1 \times 10^{-5} \mathrm{M}$ & 5 & 5.08 & $101.6 \pm 0.67$ \\
\hline $1 \times 10^{-7} \mathrm{M}$ & 7 & 6.98 & $99.7 \pm 0.49$ \\
\hline *values are mean of three determinations \\
\hline
\end{tabular}

Table 2: Precision of the potentiometric method for Moxi determination. 


\begin{tabular}{|c|c|c|}
\hline \multicolumn{2}{|l|}{ Parameter } & \multirow{2}{*}{\begin{tabular}{|l} 
Recovery\% \pm RSD* \\
$99.7 \pm 0.85$ \\
\end{tabular}} \\
\hline Standard conditions & & \\
\hline \multirow[t]{2}{*}{$\mathrm{pH}$} & 1.5 & $99.3 \pm 0.52$ \\
\hline & 2.5 & $98.9 \pm 0.50$ \\
\hline \multirow[t]{2}{*}{ Temperature $\left({ }^{\circ} \mathrm{C}\right)$} & 30 & $98.5 \pm 0.89$ \\
\hline & 40 & $96.4 \pm 0.99$ \\
\hline \multirow[t]{2}{*}{ Volume of buffer $(\mathrm{mL})$} & 2 & $99.1 \pm 0.25$ \\
\hline & 8 & $99.3 \pm 0.42$ \\
\hline \multirow[t]{2}{*}{ Reaction time (sec) } & 2 & $97.4 \pm 0.47$ \\
\hline & 10 & $99.0 \pm 0.39$ \\
\hline
\end{tabular}

Table 3: Robustness of potentiometric method for Moxi determination.
Robustness of potentiometric method for Moxi: Robustness was examined by evaluating the influence of small variation in the method variables on its analytical performance. In these experiments, one parameter was changed, whereas the others were kept unchanged, and the recovery percentage was calculated each time. It was found that small variables did not significantly affect the procedures, recovery values were shown in Table 3 .

Analysis of pharmaceutical formulations: A proposed method was applied to the pharmaceutical formulations and indicates the high accuracy of the proposed method for determination of Moxi. The proposed method has advantage of being virtually free from interferences by excipients. The percentage was $99.5 \pm 0.84$.

Recovery study of the potentiometric method: To a fixed amount of the drug in the dosage form and pure drug (the standard) were added at five different levels and the total was found by the proposed method each test was performed in triplicate. Table 4 revealing good accuracy and no interference from excipients. Recovery was calculated as the amount found / amount taken $\times 100$. Values are mean \pm R.S.D. for three determinations.

\begin{tabular}{|c|c|c|c|c|}
\hline Sample content M & Standard added $\mathrm{M}$ & p C & Found $\log c$ & Recovery $(\% \pm \text { RSD })^{*}$ \\
\hline $1 \times 10^{-4}$ & $1 \times 10^{-4}$ & 3.7 & 3.61 & $97.3 \pm 0.28$ \\
\hline $1 \times 10^{-4}$ & $2 \times 10^{-4}$ & 3.5 & 3.41 & $97.16 \pm 0.50$ \\
\hline $1 \times 10^{-4}$ & $3 \times 10^{-4}$ & 3.4 & 3.26 & $95.88 \pm 0.29$ \\
\hline $1 \times 10^{-4}$ & $4 \times 10^{-4}$ & 3.3 & 3.14 & $95.2 \pm 0.52$ \\
\hline $1 \times 10^{-4}$ & $5 \times 10^{-4}$ & 3.2 & 3.06 & $95.6 \pm 0.30$ \\
\hline
\end{tabular}

Table 4: Recovery of the potentiometric method of Moxi.

The sensitivity: The sensitivity was tested by adding some inorganic salts and diluted acids and bases, it was found that the electrode shows excellent sensitivity toward testing species with RSD less than $2 \%$.

Reproducibility: The electrode response shows excellent repeatability during analysis and very stable response with intraday RSD did not exceeded $2 \%$, and interday analysis with RSD less than $5 \%$.

\section{Conclusion}

It can be concluded that Moxi-ZnO-ISE offers a viable technique for the direct determination of Moxi in pharmaceutical preparations. The sensor allows simple, rapid, and reproducible determination over a wide linear range of concentration with the same sensitivity without the need of complex sample manipulations. The sensor exhibits a good selectivity towards the drug in the presence of various pharmaceutical recipients, long life time and time- labor saving.

The procedure avoid the usual pretreatment steps necessary for Moxi assays and presents some general advantages over common chromatographic and spectroscopic procedure, it makes use of less sophisticated equipments (there for being easier to operate and providing lower cost of analysis ) and surpasses color and turbidity problems associated with suspensions and colloids.

Sensor accomplished LOD and LOQ of $0.127 \mu \mathrm{M}, 0.3836 \mu \mathrm{M}$, respectively with a fast response time of less than 5 seconds.

\section{Acknowledgment}

The authors gratefully acknowledge Prof. Omer Nur from (Linköping University, Norrköping, Sweden) for providing facilities to accomplish this work. And Dr. Manal Siyam for analysis samples by SEM in Naturkundi Museum laboratories- Berlin - Germany.

\section{References}

1. Andriole VT (2000) The Quinolones: history and overview (3rd edn). Harcourt science \& technology company, California, London.

2. Brown FA, Clark C, Bozdogan B, Dewasse BE, Jacobs MR, et al. (2002) Single and multi-step resistance selection study in Streptococcus pneumoniae comparing ceftriaxone with levofloxacin, gatifloxacin and moxifloxacin. International Journal of Antimicrobial Agents 20: 93-99.

3. Hefnawy MM, Homoda AM, Abounassif MA, Alanazi AM, Al-Majed A, et al. (2014) Potentiometric determination of moxifloxacin in some pharmaceutical formulation using PVC membrane sensors. Chemistry Central J 8: 59-67.

4. Motwani SK, Chopra S, Ahmad FJ, Khar RK (2007) spectrophotometric methods for the estimation of moxifloxacin in bulk and pharmaceutical formulations. Spectrochim Acta A 68: 250-256.

5. Elbashir AA, Ebraheem SA, Elwagee AH, Aboul-Enein HY (2013) New spectrophotometric methods for the determination of moxifloxacin in pharmaceutical formulations. Acta Chim Slov 60 :159-165.

6. Kamruzzaman M, Alam AM, Lee SH, Ragupathy D, Kim YH, et al. (2012) Spectrofluorimetric study of the interaction between europium (III) and moxifloxacin in micellar solution and its analytical application. Spectrochim Acta A 86: 375-380. 
Citation: Idress MO, Elbashir AA, Nur O (2017) Potentiometric Determination of Moxifloxacin by ZnO Nanorodes Modified ion Selective

Page 6 of 6

7. Dsugi NFA, Elbashir AA (2015) Supramolecular interaction of Moxifloxacin and $\beta$-cyclodextrin spectroscopic characterization and analytical application. Spectrochimica Acta - Part A: Molecular and Biomolecular Spectroscopy 137: 804-809.

8. Al-Ghannam SM (2008) Atomic absorption spectroscopic, conductometric and colorimetric methods for determination of some fluoroquinolone antibacterials using ammonium reineckate. Spectrochim Acta A 69: 1188-1194.

9. Radi AE, Wahdan T, Anwar Z, Mostafa H (2010) Electrochemical determination of gatifloxacin, moxifloxacin and sparfloxacin fluoroquinolonic antibiotics on glassy carbon electrode in pharmaceutical formulations. Drug Test Anal 2: 397-400.

10. Xu YH, Li D, Liu XY, Li YZ, Lu J (2010) High performance liquid chromatography assay with ultraviolet detection for moxifloxacin: validation and application to a pharmacokinetic study in Chinese volunteers. J Chromatography B 878: 3437-3441.

11. Guerra FL, Paim CS, Steppe M, Schapoval EE (2005) Biological assay and liquid chromatographic method for analysis of moxifloxacin in tablets. J AOAC Int 88: 1086-1092.

12. Kumar AK, Ramachandran G (2009) Simple and rapid liquid chromatography method for determination of moxifloxacin in plasma. J Chromatogr B 877: 1205-1208.

13. Goudah A, Poult $\mathrm{Br}$ (2009) Pharmacokinetics and tissue residues of moxifloxacin in broiler chickens. Sci 50: 251-258.

14. Cruz LA, Hall R (2005) Enantiomeric purity assay of moxifloxacin hydrochloride by capillary electrophoresis. J Pharm Biomed Anal 38: 8-13.

15. Raju B, Ramesh M, Borkar RM, Padiya R, Banerjee SK, et al. (2012) Development and validation of liquid chromatography-mass spectrometric method for simultaneous determination of moxifloxacin and ketorolac in rat plasma: application to pharmacokinetic study. Chromatography 26: 1341-1347.

16. Pranger AD, Alffenaar JW, Wessels AM, Greijdanus B, Uges DR (2010) Determination of moxifloxacin in human plasma, plasma ultrafiltrate, and cerebrospinal fluid by a rapid and simple liquid chromatographytandem mass spectrometry method. J Anal Toxicol 34: 135-141.

17. Mascini M, Pallozzi F (1974) selectivity of neutral carrier. PVC membrane electrodes. Anal Chim Acta 73: 357-359.

18. Ganjali MR, Norouzi P, Rezapour M (2006) American Scientific Publisher (ASP): 8.

19. Sakure AA, Bassmaje MS, HA Dabbeet (2015) Novel Moxifloxacin Ion Selective Electrodes for Potentiometric Determination of Moxifloxacin in Pure Form and Pharmaceutical Formulations. International J Academic Scientific Research 3: 2272-6446.

20. Hefnawy MM, Homoda AM, Abounassif MA, Alanazi AM, Al-Majed A, et al. (2014) Potentiometric determination of moxifloxacin in some pharmaceutical formulation using PVC membrane sensors. Chemistry Central Journal 8: 14-59.

21. Elghobashy MR, Rezk MR (2014) Comparative Study of Different Ionophores in Ion Selective Electrodes for Stability indicating Determination of Moxifloxacin. Anal Bioanal Electrochem 6: 461-474

22. Qin Y, Wang XD, Wang ZL (2008) Microfibre-nanowire hybrid structure for energy scavenging. Nature: 451: 809.

23. Anees A, Ansari M, Alhoshan MS, Alsalhi AS (2010) Nanostructured Metal Oxides Based Enzymatic Electrochemical Biosensors. InTech Rijeka 1: $23-46$.

24. Vayssieres L (2003) Growth of Arrayed Nanorods and Nanowires of $\mathrm{ZnO}$ from Aqueous Solutions. advanced materials 5: 464-466.

25. Zhang J, Harris AR, Cattrall RW, Bond AM (2010) Voltammetric IonSelective Electrodes for the Selective Determination of Cations and Anions. Anal Chem 82: 1624-1633.

26. Elbashir AA, Dsugi NFA, Mohmed TOM, AboulEnein HY (2014) Spectrofluorometric analytical applications of cyclodextrins. Luminescence $29: 1-7$.

27. Elbashir AA, Saad B, Mohamed AS, Saleh MI, AboulEnein HY (2007) Determination of Ofloxacin Enantiomers in Pharmaceutical Formulations by Capillary Electrophoresis. J Liquid Chromatography \& Related Technologies 31: 348-360.

28. Suliman FEO, Elbashir AA, Schmitz OJ (2015) Study on the separation of ofloxacin enantiomers by hydroxyl-propyl- $\beta$-cyclodextrin as a chiral selector in capillary electrophoresis: a computational approach. J Inclusion Phenomena and Macrocyclic Chemistry 83: 119-129.

29. Elbashir AA, Dsugi NFA, Aboul-Enein HY (2014) Supramolecular Study on the Interaction Between Ofloxacin and Methyl $\beta$-Cyclodextrin by Fluorescence Spectroscopy and its Analytical Application. J fluorescence 24: 355-361.

30. Khaled E, Hassan HNA, Mohamed GG, Ragab FA, Seleim AA (2010) $\beta$ Cyclodextrin-Based Potentiometric Sensors for Flow-Injection Determination of Acetylcholines. Int J Electrochem Sci 5: 448-458.

31. Bakker E, Pretsch E (1995) Lipophilicity of tetraphenylborate derivatives as anionic sites in neutral carrier-based solvent polymeric membranes and lifetime of corresponding ion-selective electrochemical and optical sensors. Anal Chim Acta 309: 7-17.

32. Hansen AJ (1981) Extracellular ion concentrations during cerebral ischemia. In: Zeuthen $\mathrm{T}$, editor. The Application of Ion-Selective Microelectrodes. Elsevier New York: 239-254.

33. Topic Q2 (R1) (2005) International conference of Harmonization (ICH).

34. ICH-Q2A guideline for industry March (1995) Text on validation of analytical procedures. 